BMJ Paediatrics Open

\section{Update and harmonisation of guidance for the management of diabetic ketoacidosis in children and young people in the UK}

Charlotte EM Rugg-Gunn (D) , ${ }^{1,2}$ Mark Deakin, ${ }^{3}$ Daniel B Hawcutt ${ }^{2,4}$
To cite: Rugg-Gunn CEM, Deakin M, Hawcutt DB. Update and harmonisation of guidance for the management of diabetic ketoacidosis in children and young people in the UK. BMJ Paediatrics Open 2021;5:e001079. doi:10.1136/ bmjpo-2021-001079

Received 2 March 2021 Accepted 21 May 2021
Check for updates

(c) Author(s) (or their employer(s)) 2021. Re-use permitted under CC BY. Published by BMJ.

${ }^{1}$ University of Liverpool School of Medicine, Liverpool, UK

${ }^{2}$ Department of Women's and Children's Health, University of Liverpool, Liverpool, UK

${ }^{3}$ Alder Hey Children's Hospital, Liverpool, UK

${ }^{4}$ NIHR Alder Hey Clinical Research Facility, Liverpool, UK

Correspondence to Dr Daniel B Hawcutt; dhawcutt@liverpool.ac.uk

\section{ABSTRACT}

Diabetic ketoacidosis (DKA) is a life-threatening complication of type 1 diabetes mellitus. Careful and timely intervention is required to optimise glycaemic control and reduce the risk of mortality and devastating complications. Of these, cerebral oedema is the leading cause of death, with a mortality rate of approximately $25 \%$. This article highlights the recent updates to UK fluid therapy guidelines for DKA and provides clinical context for the benefit of paediatricians and junior doctors in light of this new guidance.

\section{INTRODUCTION}

Diabetic ketoacidosis (DKA) is a potentially life-threatening metabolic complication of type 1 diabetes mellitus. Despite interventions to reduce the incidence of DKA, the National Paediatric Diabetes Audit for 2018/2019 showed that overall $20.9 \%$ of all newly diagnosed patients in the United Kingdom (UK) presented in DKA, although there is considerable regional variability. ${ }^{1}$

DKA is characterised by uncontrolled hyperglycaemia, ketosis and subsequent metabolic acidosis. As highlighted in figure 1, the clinical picture can develop insidiously due to a variable constellation of non-specific systemic signs and symptoms, including polyuria, polydipsia, weight loss, fatigue, vomiting and abdominal pain, ultimately leading to confusion, coma and death, if untreated. ${ }^{2} 3$ Due to the ambiguity of the presenting clinical features in the early stages, delays in diagnosis are common. ${ }^{4}$

Globally, the International Society for Paediatric and Adolescent Diabetes (ISPAD) guidelines are widely used for management of paediatric DKA. ${ }^{5}$ However, in the UK, it is guided by the integrated care pathways of either the British Society for Paediatric Endocrinology and Diabetes (BSPED) or the National Institute for Health and Care Excellence (NICE). The BSPED guideline evolved from the NICE guideline in 2009 due

\section{Key messages}

Updates to two UK guidelines in 2020 has improved concordance, with $0.9 \%$ sodium chloride and the Holliday-Segar formula used as a gold standard to calculate fluid maintenance requirement.

- Minor differences remain, such as the maximum weight for maintenance and the stratification of diabetic ketoacidosis or dehydration severity.

- Careful monitoring and adherence to these national guidelines is recommended and will hopefully contribute to a reduction in deaths secondary to cerebral oedema (CO).

- Further research is required to evaluate the efficacy of these new guidelines, and better understand the pathophysiology and risk factors for developing $\mathrm{CO}$.

to concerns over limited evidence that was used for its development. While there were a number of dual-serving board members, the input and additional evidence by the BSPED special interest group in DKA was thought to increase its safety. ${ }^{6}$ Both guidelines cover the diagnosis and management of type one and two diabetes in children and young people (CYP) aged under 18 years. ${ }^{7}$ Areas of particular benefit within a secondary care setting are centred on the requirements for fluid therapy, given the importance of resuscitation in preventing complications. Due to the difference in perceived risk of cerebral oedema $(\mathrm{CO})$ due to rapid fluid administration, there was discordance between the NICE and BSPED 2015 guidelines.

Specifically, the NICE 2015 guidelines were more conservative with fluid administration, in order to avoid rapid changes in osmolality. The BSPED guidelines permitted a more generous fluid allowance, and this raised concerns about precipitating $\mathrm{CO}$. The conflicting advice generated challenges in the emergency setting, with arbitrary site-specific preference rather than evidence-based medicine taking precedence. In addition to 


\section{Clinical history: \\ - Polyuria/polydipsia \\ - Weight loss \\ - Abdominal pain \\ - Weakness \\ - Vomiting \\ - Confusion}

Clinical signs:

- Dehydration

- Kussmaul breathing

- Ketotic smell

- $\quad$ Lethargy, drowsiness

Biochemistry:

- Hyperglycaemia ( $>11 \mathrm{mmol} / \mathrm{L})$

- $\quad$ Acidaemia $(\mathrm{pH}<7.3)$

- Ketosis (blood ketones $>3 \mathrm{mmol} / \mathrm{L}$ or urine ketones ++)

Potential triggers:

- Infection e.g. viral

- Interruption to insulin therapy e.g. pump malfunction or omitted doses

- Physical or emotional trauma

- Pregnancy

- Drug interactions including alcohol and particularly cocaine

Figure 1 Key signs and symptoms of diabetic ketoacidosis, adapted from Schnabel and Hedrich. ${ }^{1}$

generating uncertainty of treatment pathways increasing the risk of clinical error, the regional variability hampered service evaluation and audit of clinical practice.

Unfortunately, there is little data to establish differences in their efficacy, especially surrounding the risk of $\mathrm{CO}$ in the paediatric population. However, inadequate resuscitation is likely to increase the risk of brain injury and thus must be avoided. Further research on a national scale is required to assess this.

This article aims to highlight the considerable alterations made to the two main UK guidelines. Alongside these updates, this article will provide clinical context to paediatricians and junior doctors who are likely to treat these vulnerable groups.

\section{UPDATED GUIDANCE}

In January 2020, the BSPED published new guidance for the management of children with DKA. ${ }^{6}$ This integrated care pathway migrated further from the model of restrictive fluid replacement towards an even more flexible approach for resuscitative and maintenance fluids. The rationale for this was based on new evidence from the Pediatric Emergency Care Applied Research Network (PECARN) DKA Fluid trial, which suggested that there was no significant difference in outcomes between rapid and slower fluid administration. ${ }^{8}$ Additionally, it showed that the initial conscious level was closely related to $\mathrm{pH}$ and weakly to age, but not to blood glucose or plasma sodium level. ${ }^{89}$ While this appears to demonstrate that cerebral function is related to the severity of acidosis even in the absence of drivers of $\mathrm{CO}$, it does not negate previous evidence that fluid shift may also contribute towards CO. ${ }^{1011}$

Furthermore, there are clear risks associated with inadequate fluid replacement. A hypovolaemic state will result in systemic hypotension and ultimately, cerebral hypoperfusion which, particularly in the context of acidosis, will increase the risk of a brain injury. ${ }^{6}$

In 2008, following three deaths from CO, the South Thames Retrieval Service introduced a 'restrictive fluid' DKA guideline in the region. Subsequently, no deaths have been reported, but this is insufficient evidence on which to make definitive recommendations or guidelines. $^{12}$

More recently, in December 2020, NICE released updated guidance on the management of DKA in CYP, which was broadly concordant with BSPED, particularly with respect to more liberal fluid restriction. This was prompted by new evidence identified by NICE's surveillance team in a review of 12 studies set to determine optimal fluid therapy in CYP with DKA. The fluid protocols followed in the PECARN study were fundamental to these updates, ${ }^{8}$ as "neither the rate of administration nor the sodium chloride content of intravenous fluids significantly influenced neurologic outcomes in children with DKA'. ${ }^{8}$ Therefore, restrictions to the fluid administration, which were recommended in the $2015 \mathrm{NICE}$ guidance, 'were not necessarily required'. ${ }^{13}$ Additionally, as with the BSPED and ISPAD guidelines, the updated NICE guidance was amended to include the HollidaySegar formula, used to calculate fluid maintenance. ${ }^{67}$ Updates to both the BSPED and NICE guidelines in 2020 have a more permissive fluid rate than in the previous DKA fluid therapy guidelines.

Both BSPED and NICE recommend the following fluid maintenance requirements, using $0.9 \%$ sodium chloride without added glucose, and the Holliday-Segar formula: - $100 \mathrm{~mL} / \mathrm{kg}$ for the first $10 \mathrm{~kg}(0-10 \mathrm{~kg}$ body weight $)$. 
- $50 \mathrm{~mL} / \mathrm{kg}$ for the second $10 \mathrm{~kg}$ (10-20 kg body weight).

- $20 \mathrm{~mL} / \mathrm{kg}$ for each subsequent kilogramme $(>20 \mathrm{~kg}$ body weight).

- When calculating the total fluid replacement, subtract any initial bolus volumes from the total fluid deficit (unless the child or young person is in shock).

For insulin and electrolyte replacement requirements, both recommend ${ }^{67}$ :

- The addition of $40 \mathrm{mmol} / \mathrm{L}$ potassium chloride to all fluids (apart from the initial intravenous bolus) unless the patient is anuric or hyperkalaemic. Include this before starting the insulin infusion if hypokalaemia is observed at presentation.

- $0.9 \%$ sodium chloride should be used without added glucose unless the plasma glucose is $<14 \mathrm{mmol} / \mathrm{L}$.

- Initially assess for the presence of hyponatraemia, continue to monitor throughout treatment and treat as soon as blood glucose falls. Monitor sodium levels throughout treatment and calculate sodium initially to identify if hyponatraemia is present. This should be treated as soon as blood glucose falls. It is important to monitor as hyponatraemia and rapidly increasing sodium levels can both be signs of CO.

- Do not give intravenous sodium bicarbonate to CYP with DKA unless they have compromised cardiac contractility caused by life-threatening hyperkalaemia or severe acidosis, and you have discussed with paediatric intensivist.

- A soluble insulin infusion of between 0.05 units $/ \mathrm{kg} /$ hour and 0.1 units $/ \mathrm{kg} /$ hour, 1-2 hours after intravenous fluids have been commenced. BSPED stated that the 0.05 units $/ \mathrm{kg} /$ hour should be sufficient unless the patient is suffering from severe DKA or is an adolescent. If they are attached to a 'continuous subcutaneous insulin infusion', disconnect when starting intravenous insulin therapy. For patients already on long-acting insulin, it may be continued, and in new patients consider commencing longacting subcutaneous insulin alongside intravenous. Similarly, the NICE guidelines state that continuing subcutaneous basal insulin in a child or young person who was using a basal insulin before DKA may be continued in discussion with a diabetes specialist.

Although these guidelines now have greater cohesion, a number of minor differences remain ${ }^{16}$ :
Regarding fluid replacement, NICE have included two levels of severity of DKA, while BSPED have subdivided the stratification to include three discrete categories for severity and subsequent dehydration status, as outlined in table 1 .

- A difference remains between the maximum weight considered by the guidelines when calculating fluid deficit. Given that the maximum weight considered for each is $75 \mathrm{~kg}$ for NICE and $80 \mathrm{~kg}$ for BSPED, the maximum difference in deficit fluids could be $1850 \mathrm{~mL}(5 \% \times 75 \mathrm{~kg}=3750 \mathrm{~mL}$ for NICE compared with $7 \% \times 80 \mathrm{~kg}=5600 \mathrm{~mL}$ for BSPED).

- For patients who are clinically dehydrated, but not in shock, an intravenous $10 \mathrm{~mL} / \mathrm{kg}$ bolus of $0.9 \%$ sodium chloride is recommended on admission. This should be administered over $30 \mathrm{~min}$ (NICE) or $60 \mathrm{~min}$ (BSPED). This volume is included in the fluid replacement when calculating the total fluid deficit. NICE recommend discussing with a paediatrician experienced in DKA management before giving more than one intravenous bolus. A second bolus should only be considered if needed to improve tissue perfusion and this must be done after reassessing their clinical status.

- A delicate balance between increasing the risk of osmolar shift secondary to rapid fluid administration, with the risk of dehydration and subsequent CO due to slower fluid administration, is the foundation for the initial discrepancy between the two guidelines. Guidance from the 2018 ISPAD consensus states that this should be administered between $30 \mathrm{~min}$ and $60 \mathrm{~min}$, which falls between the two UK guidelines. ${ }^{5}$ Therefore, aiming to administer the fluid rapidly but observing for signs of potential deterioration and adjusting the rate accordingly will provide the best outcome for patients.

- In the presence of hypovolaemic shock, both NICE and BSPED recommend an intravenous $0.9 \%$ sodium chloride bolus of $20 \mathrm{~mL} / \mathrm{kg}$. BSPED recommend repeating these infusions over $15 \mathrm{~min}$ to a maximum of $40 \mathrm{~mL} / \mathrm{kg}$, before considering the introduction of inotropes, while NICE recommends administering it as soon as possible. In both guidelines, the bolus for shock is not subtracted from total fluid deficit.

- While the nomenclature varies between these two guidelines, in practice, it is likely that these

Table 1 Comparison of NICE and BSPED DKA classification and dehydration status

\begin{tabular}{|c|c|c|}
\hline Guidelines & Severity of DKA & Dehydration \\
\hline
\end{tabular}

BSPED, British Society for Paediatric Endocrinology and Diabetes; DKA, diabetic ketoacidosis; NICE, National Institute for Health and Care Excellence. 
will represent similar time frames. Administering a $20 \mathrm{~mL} / \mathrm{kg} 0.9 \%$ sodium chloride bolus to treat shock as quickly as possible should provide the best therapy for the patient.

- When calculating fluid replacement, the NICE guidelines recommend a maximum weight of $75 \mathrm{~kg}$, whereas BSPED recommend a maximum weight of $80 \mathrm{~kg}$ or $97 \mathrm{th}$ centile weight for age (whichever is lower).

- This discrepancy is unlikely to be encountered on a frequent basis in general paediatric practice. However, if the weight greatly exceeds $75 \mathrm{~kg}$, it may be more appropriate for young people to be managed according to adult guidelines due to their increased body habitus. Additionally, identifying a CYP on the 97th centile can be difficult, especially in an emergency setting, and, therefore, this may be missed.

Figure 2 highlights the key similarities and differences between the updated 2020 guidelines.

\section{COMPARISON TO INTERNATIONAL GUIDANCE}

The new guidelines released by both $\mathrm{NICE}^{7}$ and $\mathrm{BSPED}^{6}$ read similarly to those of non-UK-based origin. The 2018 consensus guidelines released by ISPAD ${ }^{5}$ in conjunction with the European Society for Paediatric Endocrinology and the Lawson Wilkins Paediatric Endocrine Society are used globally as standard guidelines for paediatric DKA management. Although the updated NICE and BSPED guidelines are very similar, as reviewed in figure 2, the BSPED guidelines appear to be most similar to the ISPAD guidelines on fluid resuscitation and electrolyte balance, with very few differences between the two.

The most pertinent similarities between the BSPED and ISPAD guidelines include giving a bolus for shock $(20 \mathrm{~mL} / \mathrm{kg})$, using the Holliday-Segar formula to determine the maintenance fluid requirements, using a maximum of $80 \mathrm{~kg}$ in weight for these calculations and stratifying the severity of DKA (into mild, moderate and severe) compared with the two classifications used by NICE (mild/moderate and severe).

In contrast to the NICE and BSPED guidelines, which state that a $0.9 \%$ sodium chloride solution must be used when considering fluid requirements, in the ISPAD guidance, either a $0.45 \%$ or $0.9 \%$ sodium chloride or a balanced salt solution (Ringer's lactate, Hartmann's solution or Plasma-Lyte) may be used. This is secondary to recent findings from randomised control trials showing no difference in cerebral injury in patients rehydrated at different rates with either $0.45 \%$ or $0.9 \%$ sodium chloride. Additionally, for those not in shock, these fluids should be infused over 30-60 min, which falls between the two 2020 guidelines (NICE states to give fluids over $30 \mathrm{~min}$ and BSPED states over $60 \mathrm{~min}$ ). Regarding the fluid bolus for those in shock, as with the NICE 2020 guidelines, the ISPAD guidelines state that it should be given 'as soon as possible'. Conversely, BSPED says this should be over
$15 \mathrm{~min}$. However, in practice, this difference in nomenclature is likely to be negligible. Also, in agreement with the NICE 2020 guidelines, the ISPAD guidelines recommend the prescription of insulin at between 0.05 units/ $\mathrm{kg} / \mathrm{hour}$ and 0.1 units $/ \mathrm{kg} / \mathrm{hour}$, where 0.05 units $/ \mathrm{kg}$ / hour is usually sufficient in mild DKA. When assessing glucose introduction, the ISPAD guidance recommends that healthcare professionals 'consider adding glucose before $17 \mathrm{mmol} / \mathrm{L}$ if falling rapidly. Otherwise $5 \%$ glucose should be added when the plasma glucose falls to approximately $14-17 \mathrm{mmol} / \mathrm{L}^{\prime}$. This is in contrast to the NICE and BSPED guidelines, which only introduce $5 \%$ glucose when it has fallen below $14 \mathrm{mmol} / \mathrm{L}$.

The Royal Children's Hospital (RCH) in Melbourne, Clinical Practice Guidelines for Diabetic Ketoacidosis, last updated in November 2018, have been adapted for statewide use with the support of the Victorian Paediatric Clinical Network. Although broadly similar, there are a few distinct differences between the RCH guidelines and those of NICE, BSPED and ISPAD. For those in shock, a $10 \mathrm{~mL} / \mathrm{kg} 0.9 \%$ sodium chloride bolus can be given, half the volume of $20 \mathrm{~mL} / \mathrm{kg}$ recommended by the other guidelines. Although initial fluid rates are based on a degree of dehydration (with the RCH stratifications varying from the other guidelines: mild $\leq 4 \%$, moderate $=4 \%-7 \%$ and severe $\geq 7 \%$ ), maintenance fluids are not calculated using the Holliday-Segar formula. Instead a detailed table is used, with the fluid requirements classified according to the different degrees of dehydration up to a maximum of $70 \mathrm{~kg}$.

However, as with the other guidelines, $40 \mathrm{mmol} / \mathrm{L}$ of potassium chloride is added to the fluid, as long as the child is not anuric or a serum potassium $\geq 5.5 \mathrm{mmol} / \mathrm{L}$. If required, these can be increased to a maximum of $60 \mathrm{mmol} / \mathrm{L}$, which is not specified in the other guidelines. Additionally, $5 \%$ glucose is added if the blood glucose is $\leq 15 \mathrm{mmol} / \mathrm{L}$, which is comparable, although this can be increased to $10 \%$ glucose if blood glucose is falling rapidly or $\leq 5 \mathrm{mmol} / \mathrm{L}$. Insulin infusion rate of 0.1 units $/ \mathrm{kg} /$ hour is recommended unless treating children under 5 years of age, children undergoing inter-hospital transfer (where limited access to biochemical monitoring) or children with blood glucose $<15 \mathrm{mmol} / \mathrm{L}$ at the time of commencement of the insulin infusion. This is placed at the upper end of the bracket of the other guidelines, where $0.1 \mathrm{units} / \mathrm{kg} / \mathrm{hour}$ is recommended for those with severe DKA, adolescence or unresolved ketosis.

\section{CONCLUSIONS AND RECOMMENDATIONS}

The convergence of the NICE and BSPED guidelines is a welcome development in the emergency management of paediatric DKA. This will provide much needed clarity to the treating clinicians, reducing regional variation and decreasing the potential for error. Despite the pathophysiology of $\mathrm{CO}$ remaining uncertain, fluid therapy must be carefully controlled, as inadequate resuscitation is likely 


\begin{tabular}{|c|c|}
\hline NICE & BSPED \\
\hline \multicolumn{2}{|c|}{ If in shock $-20 \mathrm{ml} / \mathrm{kg}$ bolus of $0.9 \%$ sodium chloride. } \\
\hline \multicolumn{2}{|c|}{$\begin{array}{l}\text { When calculating the total fluid replacement, subtract any initial bolus volumes from the } \\
\text { total fluid deficit (if in shock - do not include the bolus volumes). }\end{array}$} \\
\hline In shock - bolus given as soon as possible. & In shock - bolus given over 15 minutes. \\
\hline \multirow[t]{2}{*}{$\begin{array}{l}\text { Not in shock - bolus given over } 30 \\
\text { minutes. }\end{array}$} & $\begin{array}{c}\text { Reassess and further boluses of } 10 \mathrm{ml} / \mathrm{kg} \\
\text { up to a total of } 40 \mathrm{ml} / \mathrm{kg} \text { - then consider } \\
\text { inotropes. }\end{array}$ \\
\hline & $\begin{array}{c}\text { Not in shock - bolus given over } 60 \\
\text { minutes. }\end{array}$ \\
\hline \multicolumn{2}{|c|}{ Fluid requirement $=$ Deficit + Maintenance } \\
\hline \multicolumn{2}{|c|}{ Hourly rate $=(($ Deficit - any initial bolus $) / 48$ hours $)+$ Maintenance per hour } \\
\hline \multirow{3}{*}{$\begin{array}{l}\text { Mild to moderate DKA (blood } \mathrm{pH} 7.1 \text { or } \\
\text { above) }=5 \% \text { dehydration. } \\
\text { Severe DKA (blood pH below } 7.1 \text { ) }=10 \% \\
\text { dehydration. }\end{array}$} & $\begin{array}{c}\text { Mild DKA (venous } \mathrm{pH} 7.2-7.29 \text { or } \\
\text { bicarbonate }<15 \mathrm{mmol} / \mathrm{l})=5 \% \\
\text { dehydration. }\end{array}$ \\
\hline & $\begin{array}{l}\text { Moderate DKA (venous } \mathrm{pH} 7.1-7.19 \text { or } \\
\text { bicarbonate }<10 \mathrm{mmol} / \mathrm{l})=7 \% \text { dehydration. }\end{array}$ \\
\hline & $\begin{array}{l}\text { Severe DKA (venous } \mathrm{pH} \text { less than } 7.1 \text { or } \\
\text { bicarbonate }<5 \mathrm{mmol} / \mathrm{l})=10 \% \\
\text { dehydration. }\end{array}$ \\
\hline $\begin{array}{l}\text { Fluid maintenance: } 0.9 \% \text { sodium chloride } \mathrm{w} \\
\qquad(100 \mathrm{ml} / \mathrm{kg} \text { for the first } 10 \mathrm{~kg}, 50 \mathrm{ml} / \mathrm{kg} \mathrm{f} \\
\text { subsec }\end{array}$ & $\begin{array}{l}\text { lout added glucose, Holliday-Segar formula. } \\
\text { the second } 10 \mathrm{~kg} \text {, and } 20 \mathrm{ml} / \mathrm{kg} \text { for each } \\
\text { ent } \mathrm{kg} \text { ) }\end{array}$ \\
\hline \multicolumn{2}{|c|}{ Given over 48 hours } \\
\hline $\begin{array}{l}\text { Maximum weight of } 75 \mathrm{~kg} \text { in the Holliday- } \\
\text { Segar formula }\end{array}$ & $\begin{array}{l}\text { Maximum weight of } 80 \mathrm{~kg} \text { or } 97^{\text {th }} \text { centile } \\
\text { weight for age (whichever is lower) in the } \\
\text { Holliday-Segar formula }\end{array}$ \\
\hline \multicolumn{2}{|c|}{$\begin{array}{l}\text { All fluids (except any initial boluses) contain } 40 \mathrm{mmol} / \text { litre (or } 20 \mathrm{mmol} / 500 \mathrm{ml} \text { ) potassium } \\
\text { chloride, unless they have renal failure or hyperkalaemia. Do not delay potassium } \\
\text { replacement. }\end{array}$} \\
\hline \multicolumn{2}{|c|}{$\begin{array}{l}\text { Monitor serum sodium levels - they should rise as DKA is treated. Falling serum sodium is } \\
\text { a sign of possible cerebral oedema. Use corrected sodium values = measured sodium + } \\
\text { ((glucose }-5.6) / 3.5)\end{array}$} \\
\hline \multicolumn{2}{|c|}{$\begin{array}{l}\text { Start intravenous insulin infusion 1-2 hours after beginning intravenous fluid therapy, } \\
\text { disconnect continuous subcutaneous insulin infusion (CSII). }\end{array}$} \\
\hline $\begin{array}{l}\text { Use a soluble insulin infusion at a dosage } \\
\text { between } 0.05 \text { and } 0.1 \text { units } / \mathrm{kg} / \mathrm{hour} \text {. Do } \\
\text { not give bolus doses of intravenous insulin. }\end{array}$ & $\begin{array}{c}0.05 \text { units } / \mathrm{kg} / \text { hour would be sufficient in } \\
\text { most cases, but consider } 0.1 \text { units } / \mathrm{kg} / \mathrm{hr} \text { in } \\
\text { severe DKA. }\end{array}$ \\
\hline \multicolumn{2}{|c|}{$\begin{array}{l}\text { When plasma glucose concentration falls below } 14 \mathrm{mmol} / \text { litre, change fluids to } 0.9 \% \\
\text { sodium chloride with } 5 \% \text { glucose and } 40 \mathrm{mmol} / \text { litre potassium chloride. }\end{array}$} \\
\hline
\end{tabular}

Figure 2 Flowchart demonstrating the similarities and differences between the 2020 updated guidelines. BSPED, British Society for Paediatric Endocrinology and Diabetes; DKA, diabetic ketoacidosis; NICE, National Institute for Health and Care Excellence.

to increase the risk of brain injury and thus must be avoided.

There is emerging evidence for a more judicious approach in the management of $\mathrm{DKA}^{9}$ and the NICE and BSPED guidelines are now largely concordant in this regard. A number of minor differences in the guidelines remain, but these are unlikely to profoundly influence patient management or outcomes. As both guidelines have changed considerably since their conception, and now have only minor differences, it could be argued that there is no benefit of two guidelines. The existence of two guidelines in the UK is primarily historical, with both 
guideline-producing groups having good reason to be interested in this area. However, the UK would, in our opinion, be better served with a single set of guidance to avoid confusion and harmonise practice.

Despite this, it is imperative that the incidence of $\mathrm{CO}$ continues to be monitored following a change to the guidelines and, in addition, this may offer insights into the underlying pathophysiological basis and effective preventative measures.

In the meantime, for junior clinicians treating DKA in CYP, close supervision by experienced paediatricians, careful monitoring and adherence to a single-set of evidence-based guidelines are likely to translate into better outcomes for this challenging condition.

Contributors Concept: MD. Writing: CEMR-G, DBH and MD. Editing: DBH and MD.

Funding The authors have not declared a specific grant for this research from any funding agency in the public, commercial or not-for-profit sectors.

Competing interests None declared.

Patient and public involvement Patients and/or the public were not involved in the design, or conduct, or reporting, or dissemination plans of this research.

Patient consent for publication Not required.

Provenance and peer review Not commissioned; externally peer reviewed.

Data availability statement Data sharing not applicable as no datasets generated and/or analysed for this study. Not applicable.

Open access This is an open access article distributed in accordance with the Creative Commons Attribution 4.0 Unported (CC BY 4.0) license, which permits others to copy, redistribute, remix, transform and build upon this work for any purpose, provided the original work is properly cited, a link to the licence is given, and indication of whether changes were made. See: https://creativecommons.org/ licenses/by/4.0/.

ORCID iD

Charlotte EM Rugg-Gunn http://orcid.org/0000-0003-1989-3489

\section{REFERENCES}

1 Schnabel A, Hedrich CM. Childhood vasculitis. Front Pediatr 2018;6:421.

2 Wolfsdorf J, Glaser N, Sperling MA, et al. Diabetic ketoacidosis in infants, children, and adolescents: a consensus statement from the American diabetes association. Diabetes Care 2006;29:1150-9.

3 Ribero S, Sciascia S, Borradori L, et al. The cutaneous spectrum of lupus erythematosus. Clin Rev Allergy Immunol 2017;53:291-305.

4 Unnikrishnan R, Shah VN, Mohan V. Challenges in diagnosis and management of diabetes in the young. Clin Diabetes Endocrinol 2016;2.

5 Wolfsdorf Jl, Glaser N, Agus M, et al. ISPAD clinical practice consensus guidelines 2018: diabetic ketoacidosis and the hyperglycemic hyperosmolar state. Pediatr Diabetes 2018;19 Suppl 27:155-77.

6 Integrated care pathway for the management of children and young people with diabetic ketoacidosis British Society for paediatric endocrinology and diabetes, 2020. Available: https://www.bsped. org.uk/media/1742/dka-icp-2020-v1_1.pdf

7 Diabetes (type 1 and type 2) in children and young people: diagnosis and management: NICE guideline NG18, 2020. Available: https://pathways.nice.org.uk/pathways/diabetes-in-childrenand-young-people/diabetic-ketoacidosis-in-children-and-youngpeople\#content=view-node\%3Anodes-recognition-referral-anddiagnosis

8 Kuppermann N, Ghetti S, Schunk JE, et al. Clinical trial of fluid infusion rates for pediatric diabetic ketoacidosis. N Engl J Med 2018;378:2275-87.

9 Edge JA, Roy Y, Bergomi A, et al. Conscious level in children with diabetic ketoacidosis is related to severity of acidosis and not to blood glucose concentration. Pediatr Diabetes 2006;7:11-15.

10 Duck SC, Wyatt DT. Factors associated with brain herniation in the treatment of diabetic ketoacidosis. J Pediatr 1988;113:10-14.

11 Arieff Al, Kleeman CR. Studies on mechanisms of cerebral edema in diabetic comas. Effects of hyperglycemia and rapid lowering of plasma glucose in normal rabbits. J Clin Invest 1973;52:571-83.

12 Lillie J, Boot E, Tibby SM, et al. Management of fluids in paediatric diabetic ketoacidosis: concerns over new guidance. Arch Dis Child 2020;105:1019-20.

13 National Institute for Health and Care Excellence. Diabetes (type 1 and type 2) in children and young people: diagnosis and management. Evidence reviews for fluid therapy for the management of diabetic ketoacidosis. guideline version (draft); 2020. 